University of Nebraska - Lincoln

DigitalCommons@University of Nebraska - Lincoln

2000

\title{
Severe Anemia in Young Children After High and Low Malaria Transmission Seasons in the Kassena-Nankana District of Northern Ghana
}

\author{
Kwadwo A. Koram \\ Noguchi Memorial Institute for Medical Research, Kkoram@noguchi.mimcom.net \\ Francis K. Nkrumah \\ Noguchi Memorial Institute for Medical Research, Fnkrumah@noguchi.mimcom.net \\ Seth Owusu-Agyei \\ Navrongo Health Research Centre, Sowusu-Agyei@navrongo.mimcom.net \\ Fred N. Binka \\ Navrongo Health Research Centre, Fbinka@africaonline.co.gh \\ Greg Utz \\ U.S. Naval Medical Research Unit \#3 \\ See next page for additional authors
}

Follow this and additional works at: https://digitalcommons.unl.edu/usnavyresearch

Koram, Kwadwo A.; Nkrumah, Francis K.; Owusu-Agyei, Seth; Binka, Fred N.; Utz, Greg; Baird, Kevin J.; and Hoffman, Steven L., "Severe Anemia in Young Children After High and Low Malaria Transmission Seasons in the Kassena-Nankana District of Northern Ghana" (2000). U.S. Navy Research. 50.

https://digitalcommons.unl.edu/usnavyresearch/50

This Article is brought to you for free and open access by the U.S. Department of Defense at DigitalCommons@University of Nebraska - Lincoln. It has been accepted for inclusion in U.S. Navy Research by an authorized administrator of DigitalCommons@University of Nebraska - Lincoln. 


\section{Authors}

Kwadwo A. Koram, Francis K. Nkrumah, Seth Owusu-Agyei, Fred N. Binka, Greg Utz, Kevin J. Baird, and Steven L. Hoffman 


\title{
SEVERE ANEMIA IN YOUNG CHILDREN AFTER HIGH AND LOW MALARIA TRANSMISSION SEASONS IN THE KASSENA-NANKANA DISTRICT OF NORTHERN GHANA
}

\author{
KWADWO A. KORAM, SETH OWUSU-AGYEI, GREG UTZ, FRED N. BINKA, J. KEVIN BAIRD, \\ STEPHEN L. HOFFMAN, AND FRANCIS K. NKRUMAH \\ Noguchi Memorial Institute for Medical Research, University of Ghana, Legon, Ghana; Navrongo Health Research Centre, \\ Ministry of Health, Navrongo, Ghana; United States Naval Medical Research Unit Number Three, Cairo, Egypt; \\ Naval Medical Research Center, Silver Spring, Maryland
}

\begin{abstract}
Malaria and anemia accounted for $41 \%$ and $18 \%$ respectively of hospital deaths in the Kassena-Nankana district of northern Ghana during 1996. We measured hemoglobin $(\mathrm{Hb})$, malaria prevalence, and anthropometric indices of 6-24-month-old infants and young children randomly selected from this community at the end of the high (May-October, $\mathrm{n}=347$ ) and low (November-April, $\mathrm{n}=286$ ) malaria transmission seasons. High transmission season is characterized by rainfall (the equivalent of $800-900 \mathrm{~mm} / \mathrm{yr}$.), while the remaining months receive less than $50 \mathrm{~mm} /$ yr. Severe anemia, defined as $\mathrm{Hb}<6.0 \mathrm{~g} / \mathrm{dL}$, was $22.1 \%$ at the end of the high transmission season compared to $1.4 \%$ at the end of the low transmission season (Odds Ratio [OR] $=20.1$; 95\% CI: 7.1-55.3). Parasitemia was $71 \%$ and $54.3 \%$ at these time points $(\mathrm{OR}=2.1 ; 95 \% \mathrm{CI}: 1.5-2.9)$. Nutritional anemia appeared to have little impact upon this seasonal difference since anthropometric indices were comparable. Although the relative contributions of other causes of severe anemia were not assessed, repeated malaria infections may be a primary determinant of severe anemia among infants and young children during the high transmission season.
\end{abstract}

\section{INTRODUCTION}

Anemia is one of the leading causes of childhood morbidity and mortality worldwide. ${ }^{1}$ In many malaria-endemic areas, anemia is among the leading causes of morbidity and mortality in hospitalized patients. It has been observed that in malaria-endemic areas, the incidence of severe anemia and age-specific rates of anemia strongly correlate with the intensity of Plasmodium falciparum transmission, ${ }^{2}$ and that significant improvements in hematological indices have been seen after malaria control trials. ${ }^{3,4}$ While there may be several causes for the anemia, $P$. falciparum infection is believed to be a major contributory factor to the etiology of severe anemia seen in malaria endemic areas. This may be a result of direct destruction of parasitized red blood cells through immune mechanisms that destroy both parasitized and non-parasitized red cells, or suppression of the bone marrow as a result of the infection. Kurtzhals and others have recently reported that some of these mechanisms may operate in asymptomatic infections in Ghanaian school children. ${ }^{5}$ We report here the prevalence of severe anemia (hemoglobin concentration $<6.0 \mathrm{~g} / \mathrm{dL}$ ) seen among infants and young children aged 6-24 months at the end of the high and low malaria transmission seasons in the Kassena-Nankana district. This study was part of a larger study that investigated the incidence of new malaria infections among the population which will be reported separately.

\section{MATERIALS AND METHODS}

Study area. The study was conducted in the KassenaNankana district in northern Ghana, an area that has been demographically well-characterized. ${ }^{6}$ In summary, the district lies in the sub-Sahelian region of West Africa and is bounded on the north by part of the international border between Ghana and Burkina Faso. Annual rainfall averages approximately $850 \mathrm{~mm}$, almost all of which occurs in the wet months of May-September, the rest of the year being dry. One of the main features of the area is a large reservoir in the center of the district that provides water for irrigation. Malaria transmission in the district occurs throughout the year, although there is very little transmission towards the end of the dry season, except for compounds sited near the few permanent bodies of water. ${ }^{6}$

Study population. The district population of approximately 175,000 has been followed regularly since 1993 . The children who participated in the present study were randomly selected from enumeration clusters of the Navrongo Demographic Surveillance System (NDSS). Two cross-sectional surveys were conducted at the end of the low and high malaria transmission seasons to select children for a malaria incidence study. Children were eligible to enter malaria incidence study if they were aged between 6 and 24 months at the beginning of the study, were not suffering from any acute or chronic illness at the time of enrollment, were going to reside in the area for the following 6 months, and their parent(s) or guardian(s) agreed to their participation in the study. Investigational review boards at the Naval Medical Research Centre, NAMRU \#3, and the Ministry of Health, Ghana, approved the study protocol.

At enrollment, all the children were weighed, examined physically for signs of illness, and had their axillary temperature taken. A blood smear was made for the identification and quantification of malaria parasites and hemoglobin estimated using a Hemocue ${ }^{\circledR}$ photometer (Leo Diagnostics, Sweden). They were also screened for the presence of glucose 6 phosphate dehydrogenase (G6PD) deficiency using a qualitative visual fluorescence method for the presence of G6PD in whole blood (Sigma Diagnostics, St. Louis, Mo.). The test is used to distinguish normal from grossly deficient samples. Hemoglobin genotype was determined by gel electrophoresis of a filter paper blot at Noguchi Memorial Institute for Medical Research. All children who qualified and whose parents gave informed consent to take part in the study were then enrolled. Children with hemoglobin concentrations less than $6 \mathrm{~g} / \mathrm{dL}$ were excluded from the associated 
TABLE 1

General characteristics of study children

\begin{tabular}{|c|c|c|}
\hline & $\begin{array}{l}\text { First child cohort (end of high } \\
\text { transmission season) } n=347\end{array}$ & $\begin{array}{l}\text { Second child cohort (end of low } \\
\text { transmission season) } n=286\end{array}$ \\
\hline Mean age (mo.) $(95 \% \mathrm{CI})$ & $15.0(14.4,15.6)$ & $14.8(14.1,15.4)$ \\
\hline \multicolumn{3}{|l|}{ Sex } \\
\hline Male (\%) & 51.9 & 50.2 \\
\hline Female $(\%)$ & 48.1 & 49.8 \\
\hline Mean WFA-z-Score $(95 \% \mathrm{CI})$ & $-2.20(-2.3140,-2.0264)$ & $-2.19(-2.3471,-2.0366)$ \\
\hline$\%$ with G6PD deficiency & 7.1 & 10.05 \\
\hline \multicolumn{3}{|l|}{ Hb phenotype $(\%)$} \\
\hline A & 66.2 & 69.6 \\
\hline $\mathrm{AS} / \mathrm{AC}$ & 29.7 & 26.9 \\
\hline $\mathrm{SS} / \mathrm{SC} / \mathrm{CC}$ & 4.1 & 3.5 \\
\hline
\end{tabular}

malaria incidence study but are included in this report. All blood slides were stained with Geimsa stain and examined under oil immersion with a light microscope (ocular magnification $\times 1000$ ). All microscopic examinations were done the same day by the study microscopist. Parasite densities were estimated by determining the number of parasites per 200 white blood cells and multiplying by 40 . A slide was declared negative after the examination of 100 high power $(1,000 \times)$ fields.

Data analysis. Differences between the two child cohorts (high and low transmission seasons) with respect to malariometric indices were tested using $\chi^{2}$ for proportions and Student's $t$-distribution for means. Parasite counts were $\log$ transformed $[\log (x+1)]$ and densities reported as geometric mean densities [antilog of $\sum \log ((x+1) / n)$ where $x$ is the parasite count per $\mu l$ of blood and $n$ is the total number of children with parasitemia]. Statistical significance is reported at $P<0.05$.

\section{RESULTS}

A total of 347 children were screened at the end of the high transmission season in November 1996 and 286 children were screened at the end of the low transmission season in May 1997. The two child cohorts were comparable in terms of age, sex, and anthropometric characteristics (Table 1) as expected because each child cohort was randomly selected from the database of the Navrongo Demographic Sur- veillance System. The prevalence of G6PD deficiency and hemoglobinopathies were also similar in the two groups of children; no episode of hemolysis was observed following administration of primaquine for radical cure.

Table 2 shows the results of univariate analysis comparing children seen at the end of the high transmission season with those seen at the end of the low transmission season. An arbitrary hemoglobin concentration of $6.0 \mathrm{~g} / \mathrm{dL}$ was used to define eligibility for the malaria-incidence study on the grounds of anemia. Based on this criterion, more than one out of every 5 children $(22.1 \%)$ screened at the end of the high transmission season was found to be ineligible. This figure was significantly lower at the end of the low transmission season $(1.4 \%)$; odds ratio $(\mathrm{OR}[95 \% \mathrm{CI}]=20.1$ $[7.1,55.3]) ; P<0.0001$. At the end of the high transmission season, the mean hemoglobin concentration was $7.2 \mathrm{~g} / \mathrm{dL}$ (7.0, 7.4) compared to $8.9(8.7,9.1)$ at the end of the low transmission season $(P<0.0001)$. Figure 1 shows the distribution of hemoglobin values seen among the two child cohorts. Almost all hemoglobin values below $6 \mathrm{~g} / \mathrm{dL}$ were seen at the end of the high transmission season while hemoglobin values above $12 \mathrm{~g} / \mathrm{dL}$ were mainly seen among children at the end of the low transmission season.

The prevalence of fever (axillary temperature $\geq 37.5^{\circ} \mathrm{C}$ ) was significantly higher $(10.8 \%)$ at the end of the high transmission season (range, $37.5-39.7^{\circ} \mathrm{C}$, mean $38.1^{\circ} \mathrm{C}$ ) than at the end of the low transmission season $(3.3 \%)$ OR $=3.56$ (1.69, 7.52), $P<0.001$; (range, $37.5-39.2^{\circ} \mathrm{C}$, mean $37.9^{\circ} \mathrm{C}$ ).

TABLE 2

Comparison of the cohorts seen at the end of the high and low transmission seasons in the Kassena-Nankana district

\begin{tabular}{|c|c|c|c|c|}
\hline Characteristic & $\begin{array}{l}\text { First child cohort (end } \\
\text { of high transmission } \\
\text { season) }(\mathrm{n}=347)\end{array}$ & $\begin{array}{l}\text { Second child cohort (end of } \\
\text { low transmission season) } \\
\qquad(\mathrm{n}=286)\end{array}$ & OR $(95 \% \mathrm{CI})$ & $P$ value \\
\hline Parasite rate & $70.0 \%$ & $54.3 \%$ & $2.1(1.5,2.9)$ & 0.001 \\
\hline Parasite density ${ }^{\mathrm{a}}$ & $1074(40-103,990)$ & $1118(40-39,520)$ & & $\mathrm{NS}^{\mathrm{b}}$ \\
\hline Proportion with $\mathrm{Hb}<6.0 \mathrm{~g} / \mathrm{dL}(\%)$ & 22.1 & $1.4 \%$ & $20.1(7.1,55.3)$ & 0.0001 \\
\hline Mean Hb. $(95 \%$ CI $) \mathrm{g} / \mathrm{dl}$ & $7.2(7.0,7.4)$ & $8.9(8.7,9.1)$ & & $0.00001^{\mathrm{b}}$ \\
\hline $\begin{array}{l}\text { Proportion of children with } \mathrm{Hb}<6.0 \mathrm{~g} / \mathrm{dL} \text { and } \\
\text { parasitemia }(\%)\end{array}$ & $81.8 \%(n=66)$ & $100 \%(n=4)$ & $0(0,8.11)$ & $\mathrm{NS}^{\mathrm{c}}$ \\
\hline $\begin{array}{l}\text { Proportion of children with } \mathrm{Hb}>6.0 \mathrm{~g} / \mathrm{dL} \text { and } \\
\text { parasitemia }(\%)\end{array}$ & $67.9 \%(n=259)$ & $53.6 \%(\mathrm{n}=278)$ & $1.84(1.27,2.65)$ & 0.001 \\
\hline Proportion of children with fever (\%) & $10.8 \%$ & $3.3 \%$ & $3.56(1.69,7.52)$ & 0.0001 \\
\hline $\begin{array}{l}\text { Proportion of febrile children with severe anemia } \\
(\mathrm{Hb}<6.0 \mathrm{~g} / \mathrm{dL})(\%)\end{array}$ & $43.2 \%(n=37)$ & $0 \%(\mathrm{n}=9)$ & & $0.02^{\mathrm{c}}$ \\
\hline Proportion of febrile children with parasitemia (\%) & $71.4 \%(\mathrm{n}=37)$ & $77.8 \%(\mathrm{n}=9)$ & & NS \\
\hline
\end{tabular}

$\mathrm{OR}=$ odds ratio; $\mathrm{CI}=$ confidence interval; Gometric Mean Parasite Density (range); Student's $t$-test; Fisher's exact test, NS $=$ not significant at $P<0.05 ; \mathrm{Hb}=$ hemoglobin. 


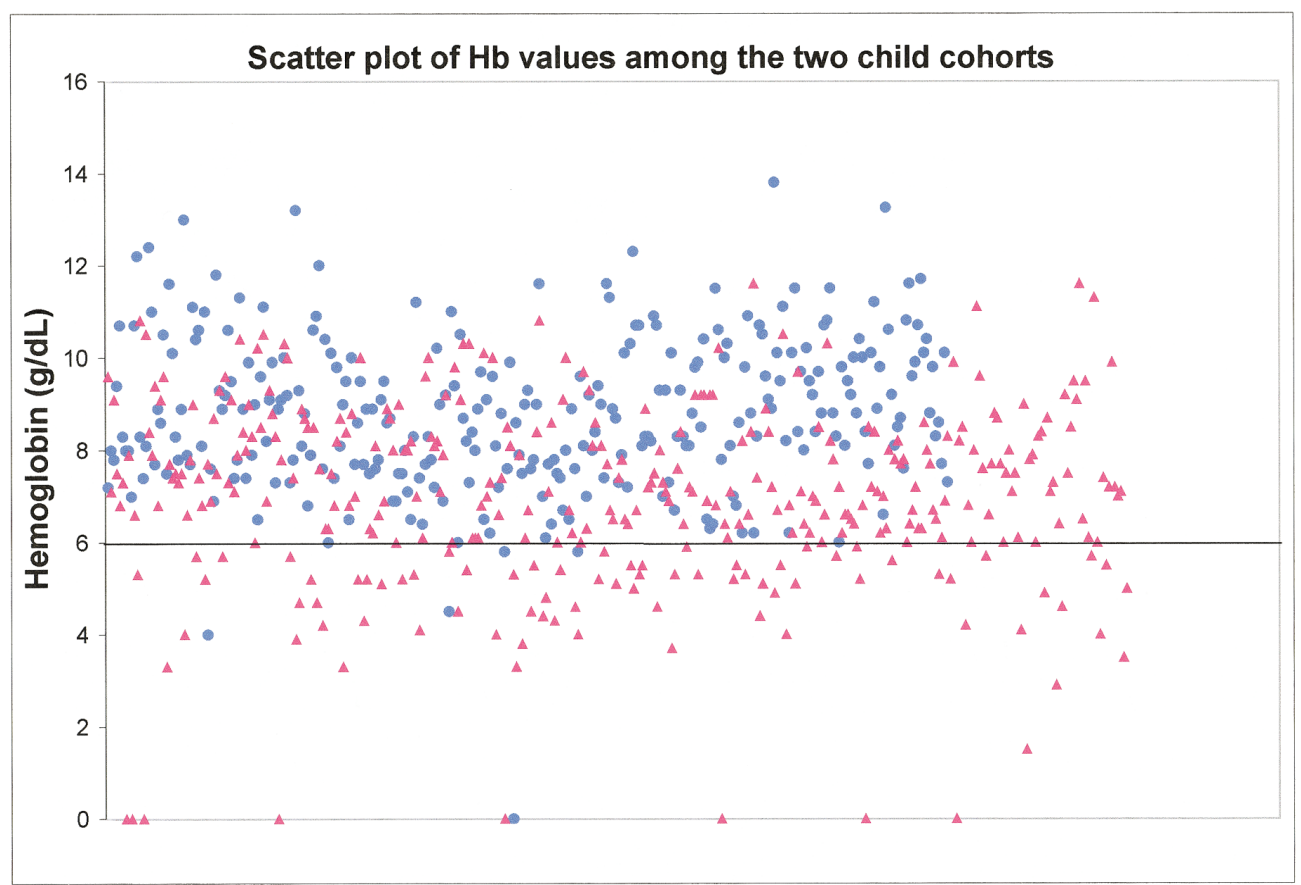

FigURE 1. Scattergram showing the distribution of hemoglobin values seen among the two cohorts, the first child cohort seen at the end of the high transmission season $(\boldsymbol{\Lambda})$ and the second child cohort seen at the end of the low transmission season $(\bullet)$. Many more children seen at the end of the high transmission season had hemoglobin values below $6 \mathrm{~g} / \mathrm{dL}$, while all of those with $\mathrm{Hb}>12 \mathrm{~g} / \mathrm{dL}$ were seen after the low transmission season. Missing values are shown on the zero line.

Forty-three percent (16 of 37) of febrile children seen at the end of the high transmission season were also severely anemic, while none of the nine febrile children at the end of the low transmission season was anemic. The mean $\mathrm{Hb}$ of febrile children at the end of the high transmission season was $6.3(5.7,7.0) \mathrm{g} / \mathrm{dL}$ compared to $8.3(7.2,9.4) \mathrm{g} / \mathrm{dL}$ for febrile children seen at the end of the low transmission season $(P$ $=0.005)$. Indeed, even for afebrile children the mean hemoglobin level was significantly lower at the end of the high transmission season (mean $\mathrm{Hb}=7.3[7.1,7.5]$ ) than at the end of the low transmission season (mean $\mathrm{Hb}=8.9$ [8.7, 9.1], $P<0.001)$. At the end of the high transmission season the mean $(\mathrm{Hb})$ was lower in those with fever than those without fever $(6.3[5.7,7.0] \mathrm{g} / \mathrm{dL}$ versus. $7.3[7.1,7.5], P=$ 0.002 ). This difference was not found at the end of the low transmission season.

Children seen at the end of the high transmission season were more likely to have $P$. falciparum infection (70.1\%) than children seen at the end of the low transmission season $(54.3 \%) ; \mathrm{OR}=2.1(1.5,2.9), P<0.001$. Infections were almost entirely due to $P$. falciparum, which accounted for more than $98 \%$ of infections seen. Other infections were due to Plasmodium malariae and Plasmodium ovale. The geometric mean parasite densities were similar at the end of both transmission seasons high transmission season, mean $=$ 1,111 , range $(40-103,900)$ and low transmission season, mean $=1,118$, range $(40-39,520)$. However, heavy infections (parasite densities $\geq 20,000 / \mu \mathrm{l}$ ) were more prevalent at the end of the high transmission season $(5.1 \%)$ compared to the low transmission season $(2.6 \%)$, but this difference was not statistically significant $(\mathrm{OR}=2.01[0.59,8.72])$. Febrile children tended to have higher parasite densities than afebrile children. At the end of the high transmission season the geometric mean parasite densities among febrile and afebrile children were $1,879(857,4,124)$ and $1,026(795$, 1,326), respectively, $(P=0.13)$. The respective mean values seen at the end of the low transmission season were 2,631 (290, 23,845) and 996 (720, 1,377), $(P=0.20)$.

The prevalence of anemia was also analyzed with respect to parasite densities. At similar intensities of parasitemia children seen at the end of the high transmission season were more likely to have lower $\mathrm{Hb}$ than children seen at the end of the low transmission season (Figure 2). The differences in the mean $\mathrm{Hb}$ concentrations were significantly different at the lower parasite densities but not at higher parasite densities. However, $\mathrm{Hb}$ concentration was still considerably less in children seen at the end of the high transmission season even at higher parasite densities.

\section{DISCUSSION}

The primary objective of the main study was to determine the incidence of $P$. falciparum infections in young children aged 6-24 months in the Kassena-Nankana district. In this paper, we have reported data acquired at the time of enrollment into the longitudinal study. A very high prevalence of anemia was observed at the end of the wet season, corresponding to the high malaria transmission season in the district. ${ }^{6}$ Among this randomly selected cohort of children, the prevalence of anemia (hemoglobin $<6.0 \mathrm{~g} / \mathrm{dL}$ ) was $22.1 \%$ at the end of the high malaria transmission season compared to $1.4 \%$ among children seen at the end of the low transmission season. The prevalence of parasitemia was $70 \%$ at the end of the high transmission season and $54.3 \%$ at the 


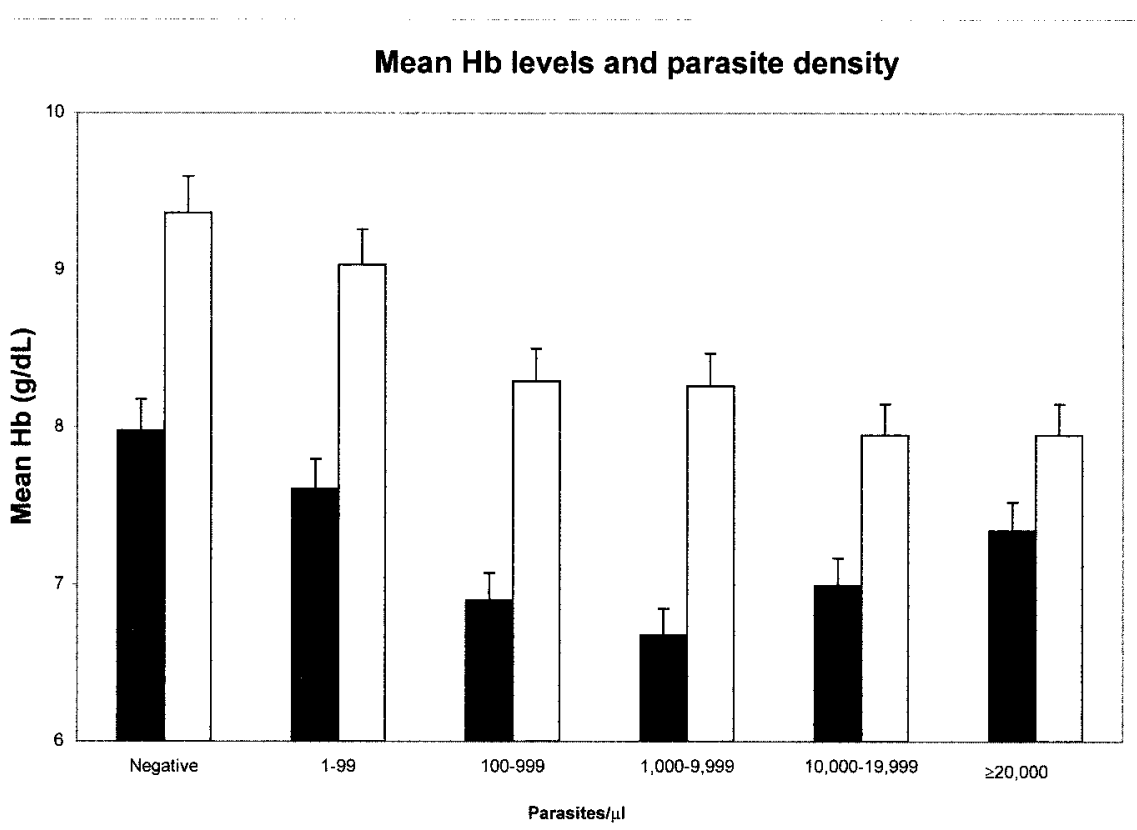

FIGURE 2. Chart showing the mean hemoglobin levels and average parasite density among children seen at the end of the high transmission season (dark bars) and at the end of the low transmission season (lighter bars). In all categories of parasite densities, mean hemoglobin values were higher at the end of the low transmission season compared to the high transmission season. Error bars are standard errors of the mean (s.e.m).

end of the low transmission season. However, there was no difference between the intensity of infection as measured by geometric mean parasitemia in those with parasites seen at the end of both transmission seasons. There was also no seasonal variation in nutritional status as measured by anthropometric indices. Febrile episodes were more common at the end of the high transmission season and a higher proportion of febrile children had coincident parasitemia.

Anemia in children is a commonly reported problem in hospitals and clinics in malaria-endemic countries. In the Kassena-Nankana district anemia accounted for approximately $20 \%$ of all admissions in the year preceding the commencement of this study. In a recent study in the same area, ${ }^{6}$ Binka and others reported significant malaria morbidity among children of 6-24 months of age. In that study, the authors reported that children in this age group suffer most from the effects of $P$. falciparum infection, although parasite rates in this population peak at a later age. Children aged 624 months had the lowest mean hemoglobin levels, the highest geometric mean parasite densities, and the highest prevalence of fever coincident with $P$. falciparum infection.

Infection with $P$. falciparum is known to be one of the major causes of childhood anemia in malaria-endemic areas. In epidemiological studies a strong correlation has been reported between the incidence of severe anemia, age-specific rates of anemia, the intensity of $P$. falciparum transmission, and also malaria control trials being followed by marked improvements in hematological indices in children. ${ }^{3,4,7} \mathrm{Ma}-$ laria transmission in this area is intense and seasonal with most of the infections occurring during the rainy season. In the main study, the malaria attack rate was 8 infections per child per year during the rainy season, compared to 5.2 per child per year during the dry season. During the dry season, almost all infections occurred during the first part of the season (attack rate $=5.1$ per child per year) compared to the latter part when the attack rate was only 0.9 infections per child per year (Baird and others, unpublished data). Children were, therefore, very likely to have suffered from repeated attacks of malaria during this period. If the attacks were frequent enough that there was not enough time for complete recovery from one infection, a marked drop in hemoglobin levels would have resulted by the end of the transmission season.

The mean hemoglobin level at the end of the high transmission season was significantly lower than that reported in the same age group of children from the previous study by Binka and others in $1994 .{ }^{6}$ With the spread of chloroquine resistance in sub-Saharan Africa, it is likely that the efficacy of chloroquine treatment will be reduced considerably in most areas resulting in poor hematological recovery, especially in children in areas of intense malaria transmission. Such a situation has been reported from sites in East Africa, where there is high prevalence of chloroquine-resistant $P$. falciparum, ${ }^{8}$ and recently in Cote d'Ivoire with only moderate level of chloroquine-resistant $P$. falciparum. ${ }^{9}$ In a recent study of the situation in Ghana, only $60 \%$ of infections in the northern part of the country were found to be sensitive to chloroquine treatment with the prevalence of resistance index responses as high as $31 \%$ (Koram and others, unpublished data). Thus, the frequent infections during the high transmission season coupled with a probable reduction in the efficacy of chloroquine treatment, the drug of choice in the area, are likely to have contributed to the $22 \%$ prevalence of severe anemia seen at the end of the high transmission season.

In this study, the parasite densities were similar at the end of both transmission seasons. The degree of anemia associated with $P$. falciparum infection has not always been pro- 
portional to the severity of parasitemia seen; anemia has often been reported when parasitemia has waned. ${ }^{10,11}$ This could be due to the fact that most reported studies determined the level of anemia and the intensity of infection at the same time. Presumably, the level of anemia is a cumulative effect of several episodes of infection and the intensity of infection determined at the same time as the hemoglobin concentration is not a good indicator of the hemoglobin concentration. The report presented here is also the result of two cross-sectional studies and would have suffered from the same deficiencies. However, in our larger incidence study, the frequency of infections was significantly higher in the wet season than in the dry season (Baird and others, unpublished data).

Malarial anemia has been postulated to be secondary to direct destruction of both infected and non-infected red blood cells and also to suppression of bone marrow function as a result of the infection..$^{5}$ Topley (1968) in The Gambia showed that the seasonal fall in hemoglobin values in adults could be prevented if malaria parasitemia was cleared or reduced by administration of pyerimethamine prophylaxis. ${ }^{12}$ The relatively high prevalence of anemia observed at the end of the high transmission season opens up the possibility of using incidence of anemia as a primary outcome variable for the effects of novel intervention tools such as vaccines, at least in areas of high malaria transmission.

Acknowledgments: We are grateful to the mothers and children of the Kassena-Nankana district who kindly allowed us into their compounds to carry out the study; to our field workers at the Navrongo Health Research Centre for help with the field work; to Mr. Charles Attiogbe of Noguchi Memorial Institute for Medical Research for technical assistance; to the staff of the Navrongo Health Research Centre for technical support; and to Dr. Tom Richie of the U.S. Naval Medical Research Center for suggestions regarding the manuscript.

Financial support: This work was supported by U.S. Naval Medical Research and Development Command independent research initiative funds and STO F6.1 work unit 61102AA0101.BXF. 1431 of the Military Infectious Diseases Research Program.

Disclaimer: The views of the authors expressed herein are their own and do not purport to reflect those of the U.S. Navy, the U.S. Department of Defense, or the Ghanaian Ministry of Health.

Authors' addresses: Kwadwo A. Koram and Francis K. Nkrumah, Noguchi Memorial Institute for Medical Research, P. O. Box LG 581,
Legon, Ghana, Tel. +233 21 501178, Fax +233 21 502182, Email: Kkoram@noguchi.mimcom.net; Fnkrumah@noguchi.mimcom.net. Seth Owusu-Agyei and Fred N. Binka, Navrongo Health Research Centre, P. O. Box 114, Navrongo, Ghana, Tel. +233 742 22380, Fax +233742 22320, Email: Sowusu-Agyei@ navrongo.mimcom.net; Fbinka@africaonline.co.gh. Greg Utz, U. S. Naval Medical Research Unit \#3, Cairo, Egypt. Kevin J. Baird and Steven L. Hoffman, Naval Medical Research Centre, Rockville, Maryland.

\section{REFERENCES}

1. WHO, 1996. Ad Hoc Committee on Health Research Relating Future Intervention Options. Investing in Health Research and Development. Geneva: WHO, Document TDR/Gen/96.1.

2. Clark HC, Tomlison WJ, 1949. In Boyd MF. ed. Malariology, Philadelphia: WB Saunders, 845.

3. Alonso PL, Lindsay SW, Armstrong JRM, Conteh M, Hill AG, David PH, Fegan G, de Francisco A, Hall AJ, Shenton FC, Cham K, Greenwood BM, 1991. The effect of insecticide treated bed nets on mortality of Gambian children. Lancet 337: $1499-1502$.

4. Greenwood BM, Greenwood AM, Snow RW, Byass P, Bennett S, Hatib-N'jie AB, 1989. The effects of malaria chemoprophylaxis given by traditional birth attendants on the course and outcome of pregnancy. Trans R Soc Trop Med Hyg 83: 589-594.

5. Kurtzhals JAL, Rodrigues O, Addae M, Commey JOO, Nkrumah FK, Hviid L, 1997. Reversible suppression of bone marrow response to erythropoietin in Plasmodium falciparum malaria. Br J Hematol 97: 169-174.

6. Binka FN, Morris SS, Ross DA, Arthur P, Aryeetey ME, 1994. Patterns of malaria morbidity and mortality in northern Ghana. Trans R Soc Trop Med Hyg 88: 381-385.

7. Molyneux L, Grammicia G, 1980. The Garki Project. Geneva, Switzerland: World Health Organization.

8. Bloland PB, Lackritz EM, Kazembe PN, Were JBO, Steketee R, Campbell CC, 1993. Beyond chloroquine: implications of drug resistance for evaluating malaria therapy efficacy and treatment policy in Africa. J Infec Dis 167: 932-937.

9. Henry MC, Eggelte TA, Watson P, Docters van Leeuwen B, Baker DA, Kluin J, 1996. Response of childhood malaria to chloroquine and fansidar in an area of intermediate chloroquine resistance in Cote d'Ivoire. Trop Med Intl Hlth 1(5): $610-615$.

10. Nkrumah FK, 1973. Severe anemia associated with malaria in children. Ghana Med J 12(1): 17-21.

11. Jilly P, Nkrumah FK, 1964. A survey of anemia in children in the Korle Bu Hospital with special reference to malaria. Ghana Med J 3: 118-124.

12. Topley E, 1968. Common anemia in rural Gambia. 3: A spontaneously remitting anemia possibly precipitated by malarial parasitaemia. Trans R SocTrop MedHyg 62: 602-604. 